\title{
Similarity of colorectal cancer in Crohn's disease and ulcerative colitis: implications for carcinogenesis and prevention
}

\author{
P M Choi, M P Zelig
}

\begin{abstract}
Colorectal cancer is the most frequent malignant complication in patients with inflammatory bowel disease. Eighty patients with colorectal cancer complicating Crohn's disease (CD) or ulcerative colitis (UC) with median ages at diagnosis of colorectal cancer of 54.5 years and 43.0 years respectively were studied. The median duration of disease to the diagnosis of cancer was long (CD 15 years; UC 18 years). Most cancers developed after more than eight years of disease (CD 75\%; UC 90\%). Patients with multiple carcinomas at diagnosis were equally common (CD 11\%; UC 12\%). Carcinoma occurred in the area of macroscopic disease in most patients (CD 85\%; UC 100\%). Mucinous and signet ring histological features were equally common (CD 29\%; UC 21\%). Dysplasia was present with similar frequency in both diseases (CD 73\%; UC $79 \%$ ). The overall five year survival rates were also similar (CD $46 \%$; UC $50 \%$ ). These findings show that carcinomas complicating $\mathrm{CD}$ and UC have strikingly similar clinicopathological features and suggest that a common underlying process, such as chronic inflammation, maybe important in the pathogenesis of colorectal carcinoma.

(Gut 1994; 35: 950-954)
\end{abstract}

Colorectal cancer is the most frequent malignant complication of inflammatory bowel disease. Since the initial description of this complication in $1925,{ }^{1}$ much has been learned about colorectal cancer in ulcerative colitis (UC). Thus, the increased cancer risk in long standing UC is now well established, and is thought to be dependent on the duration and extent of disease. ${ }^{2-8}$ Periodic colonoscopic surveillance with multiple biopsies is currently recommended as a method of identifying high risk patients. Our recent study ${ }^{9}$ suggests that surveillance colonoscopy can improve cancer related mortality in patients with long standing UC.

In comparison, colorectal cancer in Crohn's disease (CD) has not been as well studied. In fact, until recently the detection of colorectal carcinoma in inflammatory bowel disease was considered diagnostic of UC. ${ }^{10}$ However, subsequent studies ${ }^{11-13}$ have shown that the risk of developing colorectal cancer in $\mathrm{CD}$ is significant, and may be comparable to that in UC. The implications of these studies on the specific management of cancer risk in patients with $C D$ are not yet clear, particularly since only limited information is available on clinical and pathological features of this complication. Studies ${ }^{14}$ suggesting a rising incidence of $C D$ in the general population places a greater number of patients at increased risk of developing carcinoma. Therefore, an understanding of this problem is becoming critical.

Unfortunately, the basis for the increased risk of colorectal cancer in patients with either CD or UC remains even less well understood. Clearly, a better understanding of the aetiopathogenesis of cancer in inflammatory bowel disease would be extremely helpful in defining patients at highest risk and in developing an improved cancer risk management plan.

In this study, we have compared directly the features of colorectal cancer in CD and UC. We show that the clinicopathological characteristics of colorectal cancer in the two diseases are strikingly similar. We discuss evidence supporting the importance of inflammatory activity in carcinogenesis and its implication for cancer prevention in patients with inflammatory bowel disease.

\section{Methods}

The computerised medical record system at the Lahey Clinic Medical Center was used to identify patients with the diagnosis of inflammatory bowel disease or colorectal cancer, or both, (using the International Classification of Diseases 7-9) who had been seen between 1957 and 1991 . There were 6217 patients with inflammatory bowel disease, 3124 patients with CD and 3093 patients with UC. Among these patients, 80 had concomitant colorectal cancer. During this period 5266 patients with colorectal cancer but without a known history of inflammatory bowel disease were seen at the same institution among the 1020765 patients without inflammatory bowel disease.

The diagnoses of $\mathrm{CD}$ and UC were confirmed by standard clinical, roentgenographic, endoscopic, and histological criteria for these 80 patients. The onset of disease was defined as the time when the patient first experienced symptoms consistent with inflammatory bowel disease. ${ }^{6}$ The anatomical location of the colorectal cancer and its relationship to the location and macroscopic extent of inflammatory bowel disease were determined by roentgenography or colonoscopy examination. ${ }^{1516}$ Tumour histology and associated dysplasia were analysed in patients in whom \\ Accepted for publication}




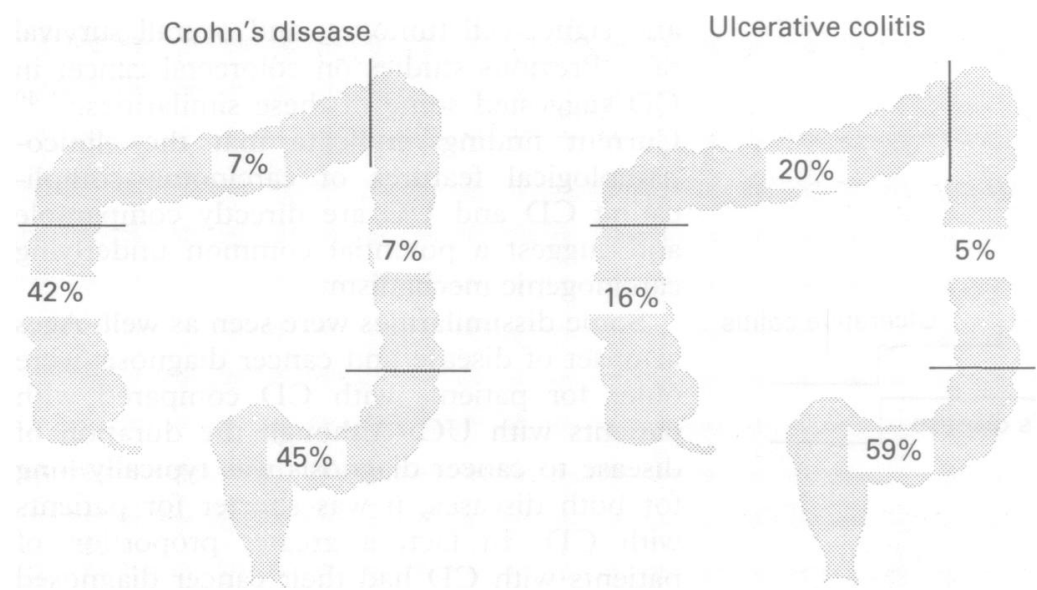

Figure 1: Anatomical distribution of cancer in patients with associated Crohn's disease and ulcerative colitis. $p=0 \cdot 04$.

this information was available. Complete data were not available for all patients. Dysplasia was not subcategorised into low grade and high grade dysplasia because of the small sample size. The Dukes's stage was confirmed pathologically in all but one patient with $C D$.

Medical records were reviewed to determine the patients' current condition. For patients whose follow up records were not up to date, telephone calls were used to determine the current status. For deceased patients, the cause of death was determined to be related to the underlying malignancy in all patients by autopsy reports or medical records, or both.

Statistical analysis was performed using the BMDP-1L statistical program (BMDP Statistical Software Inc, Los Angeles, CA). Survival distributions were calculated by the product-limit method of Kaplan and Meier. ${ }^{17}$ The statistical significance of differences between distributions were analysed by the Tarone-Ware method. Probability values are two tailed with $\mathrm{p}<0.05$ regarded as statistically significant. ${ }^{1819}$

\section{Results}

Eighty of the 6217 patients with either $C D$ or UC had colorectal cancer. Of these 80 patients, 28 had CD and 52 UC. The median age at diagnosis of $\mathrm{CD}$ of 35.5 years (range, 14-72 years) was older than the median of 25.0 years (range, $5-68$ years) in patients with UC $(p=0.001)$. The median age at diagnosis of colorectal cancer in patients with $C D$ of 54.5 years (range, $32-76$ years) was older than the median of 43.0 years (range, $17-75$ years) found in patients with UC $(p=0.005)$. The median duration of disease to the time of the diagnosis of cancer was 15 years for patients with $C D$ compared with 18 years for patients with UC $(p=0 \cdot 12)$. For reference, the median age at diagnosis of sporadic colorectal cancer during the period studied was 65.0 years (range, 7-99) for 5266 patients without inflammatory bowel disease. Thus, cancer developed at a relatively younger age in patients with CD $(p<0.001)$ and UC $(\mathrm{p}<0.001)$.

Colorectal cancer was diagnosed in seven of $28(25 \%)$ patients with CD within the first eight years of disease. In comparison, five of 52 $(10 \%)$ patients with UC were diagnosed with cancer within the first eight years of disease $(p=0.08)$. In patients with Crohn's disease, $86 \%$ of those who developed cancer within the first eight years of disease were older than 50 years of age (median age, 65; range, 35-72), compared with $57 \%$ of those with a disease duration of greater than eight years (median age, 52 ; range, $32-76 ; \mathrm{p}=0 \cdot 21$ ). In comparison, $40 \%$ of patients with UC who developed cancer within the first eight years of disease were older than 50 years of age (median age, 36; range, 19-65), compared with $34 \%$ of those with UC duration of greater than eight years (median age, 43 ; range, $17-75 ; \mathrm{p}=0.79$ ).

Mucinous carcinomas were seen in $22 \%$ of patients with CD and $15 \%$ of patients with UC $(p=0.51)$. Signet ring carcinoma was detected in $7 \%$ of patients with $\mathrm{CD}$ and $6 \%$ of patients with UC $(p=0 \cdot 81)$. Pathology specimens were available for analysis of dysplasia in 40 patients (CD 11; UC 29). Dysplasia was detected in $73 \%$ of patients with $\mathrm{CD}$ and $79 \%$ of patients with UC $(p=0.67)$.

Multiple tumours at the time of cancer diagnosis (synchronous cancer) were seen in $11 \%$ of patients with CD and $12 \%$ of those with UC $(p=0.94)$. The anatomical location of tumours in CD patients was evenly distributed between the right and rectosigmoid colon. This differed from patients with UC, in whom tumours were predominantly in the rectosigmoid area. Carcinoma of the descending and transverse colon was rare in both diseases. Overall, the anatomical distribution of colorectal cancer in two diseases was significantly different $(p=0.04 ;$ Fig 1$)$.

Among 26 patients with CD whose extent of disease was known, $73 \%$ had ileocolitis and $27 \%$ colitis. Carcinoma was found within the area of macroscopic disease ${ }^{1516}$ in $22(85 \%)$. No instance of colorectal cancer was found without concomitant colonic disease. In comparison, among 45 patients with UC whose extent of disease was known, $76 \%$ had pancolitis and $24 \%$ left sided disease. Cancer developed in the area of macroscopic disease in all 45 patients with UC $(100 \% ; p=0.05)$. Thus, cancer developed in the left colon in all 11 patients with left sided disease.

For cancer stage and survival analyses, 20 patients with UC who had undergone cancer surveillance ${ }^{9}$ were excluded to eliminate the intervention bias. In the remaining patients with cancer, the distribution of Dukes's stages in CD and UC were similar ( $p=0.91$; Table I). There were 32 deaths in these patients (CD 15; UC 17). The survival rates of the two groups were analysed using the Kaplan-Meier product-limit method to adjust for the difference in the duration of follow up. ${ }^{17}$ The analysis showed a five year survival rate of mean (SD) $46 \cdot 4(10 \cdot 1) \%$ for patients with CD (median follow up time, 2.0 years; range, $0-13.0$ years) compared with $50 \cdot 1(9 \cdot 7) \%$ for patients with UC (median follow up time, 3.6 years; range, $0-42 \cdot 6$ years). These results are shown in Figure $2(p=0.97)$ and are similar to previously reported survival data on our 


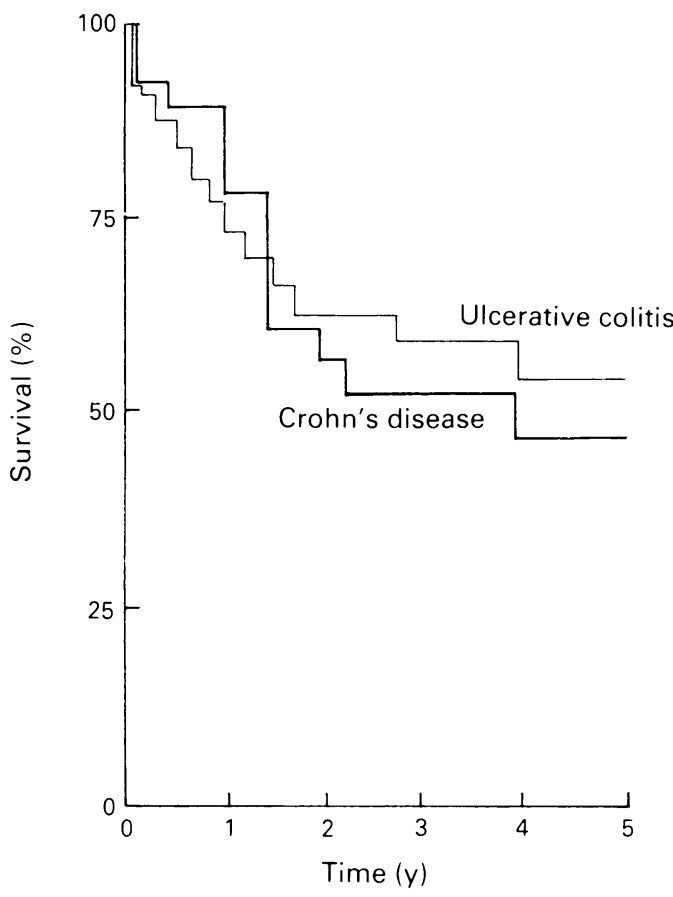

Figure 2: Overall five vear survival. The mean (SD) five year survival rate was $50.1 \%(9 \cdot 7 \%)$ for ulcerative colitis and $46 \cdot 4 \%(10 \cdot 1 \%)$ for Crohn's disease $(p=0.97)$.

patients with sporadic colorectal cancer. ${ }^{20} 21$ No difference in the five year survival rates were found for each stage between the two diseases $(p<0 \cdot 05$; Fig 3$)$. However, the five year survival rates between stages analysed for all patients with cancer were statistically significant $(\mathrm{p}<0 \cdot 001$; data not shown $)$.

\section{Discussion}

These findings show that the clinicopathological features of carcinoma complicating CD and UC are strikingly similar. Similarities include typical long duration of disease before the diagnosis of cancer, relatively young age at diagnosis of cancer compared with sporadic colorectal cancer, frequent multiple tumours at presentation, usual predominance of cancer in the area of macroscopic disease, prevalence of associated dysplasia, frequency of mucinous

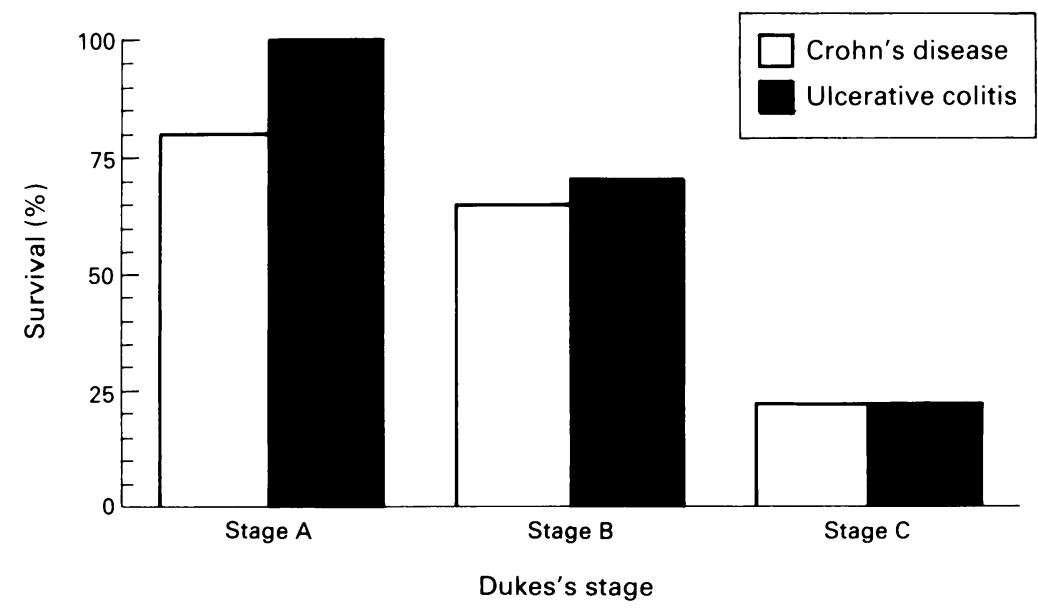

Figure 3: Five year survival in relation to Dukes's stage. The five year survival rate by each Dukes's stage between Crohn's disease and ulcerative colitis showed no significant difference $(p>0 \cdot 05)$. and signet cell tumours, and overall survival rate. Previous studies on colorectal cancer in CD suggested some of these similarities. ${ }^{22} 40$ Current findings indicate that the clinicopathological features of carcinoma complicating $\mathrm{CD}$ and UC are directly comparable and suggest a potential common underlying carcinogenic mechanism.

Some dissimilarities were seen as well. Ages at onset of disease and cancer diagnosis were older for patients with CD compared with patients with UC. Although the duration of disease to cancer diagnosis was typically long for both diseases, it was shorter for patients with CD. In fact, a greater proportion of patients with $C D$ had their cancer diagnosed within the first eight years of the onset of disease, a tendency previously noted. ${ }^{22}$ Paradoxically, the age at cancer diagnosis of patients with CD of shorter duration was older than that of the patients with a longer duration of disease.

Although these findings may be explained by sampling and referral biases, a review of the published reports showed nearly identical findings. Of 72 analysable patients (median age, 50; range, 26-77) in more than 100 reported cases, 22 colorectal cancer developed in $18(25 \%)$ within the first eight years of CD. The vast majority of these patients $(78 \%)$ were older than 50 years (median age, 59; range, 27-72) compared with only $39 \%$ of the remaining 54 patients with a duration of disease longer than eight years (median age, $47 \cdot 5$; range, $26-77 ; p=0 \cdot 005)$. Thus, a chance occurrence of sporadic colorectal cancer related to age may partly explain the shorter duration of disease before the diagnosis of cancer in these older patients.

In addition, a high proportion (57\%) of our patients with CD whose diagnosis of cancer was made within the first eight years of disease had an antecedent history of poorly characterised bowel symptoms, such as frequent loose bowel movements and vague abdominal pain, or a diagnosis of irritable bowel syndrome. It its possible that these patients had, in fact, subclinical CD. In contrast, none of the patients with a short duration of UC before the diagnosis of cancer had such a history.

Another difference was that the anatomical distribution of colorectal carcinoma differed between $\mathrm{CD}$ and UC (Fig 1). However, cancers tended to occur in areas affected by inflammatory bowel disease. In all patients with UC, cancer developed in the area of macroscopic disease, and therefore none of those with left sided colitis developed cancer in the proximal unaffected colon. Similarly, most patients with CD developed cancer in the area of macroscopic disease. Colorectal cancer did not develop in patients with small bowel $\mathrm{CD}$ only. Because $\mathrm{CD}$ often starts in the rectosigmoid and ileocaecal region, and UC invariably begins from the rectum and extends proximally, ${ }^{41}$ it seems that the anatomical distribution of cancer followed these respective sites of disease involvement.

A separate review of five small bowel cancers 
in our patients with inflammatory bowel disease also showed a similar tendency for cancer to develop in the region affected by inflammatory bowel disease. For example, in three patients with $C D$, small bowel cancer developed in the area of ileal disease (unpublished observation). This agrees with previous studies on the pattern of small bowel carcinoma in CD. ${ }^{42}$ No instance was found of small bowel cancer complicating $C D$ that affected only the colon. In addition, cancer developed at the site of the ileostomy in two previously reported patients with UC who had undergone colectomy. ${ }^{43}$ Interestingly, the precolectomy barium enema study had shown evidence of 'backwash' ileitis in both patients.

The exact comparative risks of colorectal cancer in our patients with inflammatory bowel disease is difficult to determine on the basis of current analysis, because of well described potential biases. ${ }^{44} 45$ It is nevertheless notable that the crude cumulative rate of colorectal cancer seen in our patients with CD was less than that seen in those with UC $(0.9 \% v 1.7 \%)$. This is similar to results from two of the largest population based studies ${ }^{13} 46$ in which the overall cumulative rate of colorectal cancer for their inflammatory bowel disease population, which included both low and high risk patients over a 26 year period, was $0.6 \%$ in patients with CD and $2.9 \%$ for those with UC.

This apparent difference in cancer risks may be a reflection of the different pattern of bowel involvement in the two diseases. For example, segmental involvement of disease, frequent small bowel disease without colonic involvement, and common surgical resection in $\mathrm{CD}^{4748}$ signify less absolute length of colon at risk. The decreased length of bowel affected by the disease process probably played a role in the decreased rate of colorectal cancer in patients with $C D$.

These findings suggest a common underlying carcinogenic mechanism in inflammatory bowel disease. One likely candidate is the underlying chronic inflammation 4950 shared by both diseases. Findings including the predominance of cancer in the area affected by the chronic inflammatory process, an apparent dose dependent relationship between the risk of developing cancer and the duration and extent of colonic inflammation, and the similarity of pathological features of neoplasia developing in two distinct chronic inflammatory conditions of the bowel, indicate that the increased cancer risk seen in inflammatory bowel disease may be related to the underlying chronic inflammation rather than to an undefined carcinogenic mechanism unique to either CD or UC. Results seen with other chronic inflammatory conditions such as Barrett's oesophagus ${ }^{51}$ and experimental colitis $^{52-54}$ also support this conclusion. These observations, in turn, provide an explanation for recent studies ${ }^{55-60}$ showing the efficacy of anti-inflammatory agents in the prevention of colorectal cancer and suggest their potential role as a chemopreventive measure in patients with inflammatory bowel disease.

These results also suggest a potential method of improving the current technique of colonoscopic surveillance with random biopsies at fixed interval in patients with UC. For example, these results suggest that cancer is less likely to develop in an unaffected bowel. Thus, surveillance biopsies of the proximal colon in patients with well documented, left sided UC may not be as important. On the other hand, a separate analysis ${ }^{61}$ showed that the rectosigmoid in UC is at the highest risk for the development of dysplasia and carcinoma, probably because of the invariable involvement of this region by the chronic inflammation. ${ }^{41}$ Thus, the current biopsy regimen may benefit from an increased sampling of the distal colon.

Cancer surveillance in patients with $C D$ at increased risk should probably be considered too. It is likely that patients with extensive $\mathrm{CD}$ of long duration without prior surgical resection would benefit from a surveillance programme that emphasises biopsies in the area of macroscopic disease. These results suggest that a periodic surveillance should probably start after eight years of disease. In a few people who present with CD after 50 years of age, surveillance starting at the time of the diagnosis of disease may be appropriate.

In conclusion, these results indicate that clinicopathological features of colorectal cancer complicating $\mathrm{CD}$ and UC are strikingly similar. These findings indicate a common underlying process, such as chronic inflammation, may be important in colon carcinogenesis and suggest potential methods of improving current approaches to cancer prevention in patients with inflammatory bowel disease.

We are indebted to Drs Rodger C Haggitt, Basil Rigas, and Alfred I Neugut for their critical review of the manuscript. We are grateful to members of the Department of Anatomic Pathology at the Lahey Clinic Medical Center for their help with analysis of pathologic specimens and Gerald J Heatley, MS, Sias Surgical Research Unit, for assistance with statistical ans , Sis. This study was supported by the Robert E Crozier analysis. This study was supported by the Robert E Crozier Research Fund and the Irving Family Gastroenterology Research Fellowship Award (MPZ). The preliminary result of this study was presented as an abstract during the Digestive Disease Week on May 18, 1993 in Boston, MA, USA.

1 Crohn BB, Rosenberg B. The sigmoidoscopic picture of chronic ulcerative colitis (nonspecific). Am $7 \mathrm{Med} S \mathrm{Si}$ chronic ulcerative

2 Rosenqvist $\mathrm{H}$, Ohrling $\mathrm{H}$, Lagercrantz $\mathrm{R}$, Edling $\mathrm{N}$. Ulcerative colitis and carcinoma coli. Lancet 1959; $\mathrm{i}$ : 906-8.

3 Edwards FC, Truelove SC. Course and prognosis of ulcerative colitis. Part IV. Carcinoma of colon. Gut 1964; 5: $15-22$.

4 MacDougall IPM. The cancer risk in ulcerative colitis. Lancet 1964; ii: 655-8.

5 deDombal FT, Watts JM, Watkinson G, Goligher JC. Local complications of ulcerative colitis: Stricture, pseudopolyposis and carcinoma of colon and rectum. BMF 1966; $\mathrm{i}$ : posis and

6 Devroede GJ, Taylor WF, Sauer WG, Jackman RJ, Stickler GB. Cancer risk and life expectancy of children with GB. Cancer risk and life expectancy of children
ulcerative colitis. $N$ Engl f Med 1971; 285: 17-21.

7 Kewenter J, Ahlman H, Julten L. Cancer risk in ulcerative colitis. Ann Surg 1978; 15: 824-8.

8 Greenstein AJ, Sachar DB, Smith H, Pucillo A, Papatestas $\mathrm{AE}$, Kreel I, et al. Cancer in univeral and left-sided ulcerative colitis: factors determining risk. Gastroenterology 1979; 77: 290-4

9 Choi PM, Nugent FW, Schoetz DJ, Silverman ML, Haggitt RC. Colonoscopic surveillance reduces mortality from colorectal cancer in ulcerative colitis. Gastroenterology 1993; 105: 418-24.

10 Thayer WR. Crohn's disease (regional enteritis): a look at the last 4 years. Scand f Gastroenterol 1970; 6: 165-85.

11 Weedon DD, Shorter RG, Illstrup DM, Huizenga KA, Taylor WF. Crohn's disease and cancer. $N$ Engl $f$ Med 1973; 289: 1099-103.

12 Softley A, Clamp SE, Watkinson G, Boucher LAD, Myren J, DeDombal FT. The natural history of inflammatory 
bowel disease: Has there been a change in the last 20 years? Scand f Gastroenterol 1988; 23: 20-3.

13 Ekbom A, Helmick C, Zack M, Adami H. Increased risk of large-bowel cancer in Crohn's disease with colonic involvement. Lancet 1990: 336: 357-9.

14 Binder V. Epidemiology, course and socio-economic influence of inflammatory bowel disease. Schweiz med Wschr 1988; 118: 738-42.

15 Gomes P, Boulay CD, Smith CL, Holdstock. Relationship between disease activity indices and colonoscopic findings in patients with colonic inflammatory bowel disease. Gut 1986; 27: 92-5.

16 Camilleri M, Proano $M$. Advances in the assessment of disease activity in inflammatory bowel disease. Mayo Clin Proc 1989; 64: 800-7.

17 Kaplan EL, Meier P. Nonparametric estimation from incomplete observations. F AM Stat Assoc 1958; 53: 457-81.

18 Lee ET. Statistical methods for survival data analysis. Belmont, California, Lifetime Learning Publication, 1980.

19 Tarone RE, Ware J. On distribution-free tests for equality of survival distributions. Biometrika 1977; 64: 156-60.

20 Corman ML, Veidenheimer MC, Coller JA. Colorectal carcinoma: a decade of experience at the Lahey Clinic. Dis Colon Rectum 1979; 22: 477-9.

21 deLeon ML, Schoetz DJ Jr, Coller JA, Veidenheimer MC. Colorectal cancer: Lahey Clinic experience, 1972-1976. An analysis of prognostic indicators. Dis Colon Rectum An analysis of progr

22 Hamilton SR. Colorectal carcinoma in patients with Crohn's disease. Gastroenterology 1985; 89: 398-407.

23 Petras RE, Mir-Madjlessi SH, Farmer RG. Crohn's disease and intestinal carcinoma. Gastroenterology 1987; 93: 1307-14.

24 Martinelli V, Bellucci M. Terminal ileitis and cancer of the right colon. Ann Ital Chir 1959; 36: 557-72.

25 Wein MA, Spector N. Regional ileitis complicated by adenocarcinoma: Report of a case. Am 7 Gastroenterol 1964; 41: 58-63.

26 Atwell JD, Duthie HL, Goligher JC. The outcome of Crohn's disease. Brf Surg 1965; 52: 966-72.

27 Perrett AD, Truelove SC, Massarella GR. Crohn's disease and carcinoma of colon. BMF 1968; 2: 466-8.

28 Hywel-Jones J. Colonic cancer and Crohn's disease. Gut 1969; 10: 651-4.

29 Kipping RA. Crohn's disease of the colon with carcinoma of the rectum. Proc $R$ Soc Med 1970; 63: 753

30 Hardy DG, Youngs GR. Crohn's disease and carcinoma of the rectum. Int Surg 1972; 57: 504-6.

31 Darke SG, Parks AG, Grogono JL, Pollock DJ. Adenocarcinoma and Crohn's disease - a report of cases and analysis of the literature. Br f Surg 1973; 60: 169-75.

32 Simpson S, Traube J, Riddell RH. The histologic appearance of dysplasia (precarcinomatous change) in Crohn's disease of the small and large intestine. Gastroenterology 1981; 81: 492-501.

33 Warren R, Barwick K. Crohn's colitis with carcinoma and dysplasia - report of a case and review of 100 smal and large bowel resections for Crohn's disease to detect incidence of dysplasia. Am f Surg Pathol 1983; 7: 151-9.

34 Cooper DJ, Weinstein MA, Korelitz BI. Complications of Crohn's disease predisposing to dysplasia and cancer of of Crohn's disease predisposing to dysplasia and cancer of the intestinal tract: considerations of a
program. $\mathcal{F}$ Clin Gastroenterol $1984 ; 6: 217-24$

35 Kvist N, Jacobsen O, Norgaard P, Ockelmann HH, Kvist HK, Schou G, Jarnum S. Malignancy in Crohn's disease. Scand $\mathcal{F}$ Gastroenterol 1986; 21: 82-6.

36 Wyatt MG, Houghton PW, Mortensen NJ, Williamson RC. The malignant potential of colorectal Crohn's disease. Ann R Coll Surg Engl 1987; 69: 196-8.

37 Richards ME, Rickert RR, Nance FC. Crohn's diseaseassociated carcinoma - a poorly recognized complication of inflammatory bowel disease. Ann Surg 1989; 209: 764-73.
38 Korelitz BI, Lauwers GY, Sommers SC. Rectal mucosal dysplasia in Crohn's disease. Gut 1990; 31: 1382-6.

39 Savoca PE, Ballantyne GH, Cahow CE. Gastrointestina malignancies in Crohn's disease - a 20 year experience. Dis Colon Rectum 1990; 33: 7-11.

40 Lofberg R, Brostrom O, Karlen P, Ost A, Tribukait B. Carcinoma and DNA aneuploidy in Crohn's colitis histological and flow cytometric study. Gut 1991; 32: 900-4.

41 Both H, Torp-Pederson K, Kreiner S, Hendriksen S, Binder V. Clinical appearance at diagnosis of ulcerative colitis and Crohn's disease in a regional patient group. Scand $\mathcal{f}$ Gastroenterol 1983; 18: 987-91.

42 Robeiro MB, Greenstein AJ, Heimann TM, Yamazaki Y, Aufses AH. Adenocarcinomas of the small intestine in Aufses AH. Adenocarcinomas of the small intestine in
Crohn's disease. Surg Gynecol Obstet 1991; 173: 343-9.

43 Roberts PL, Veidenheimer MC, Cassidy S, Silverman ML Adenocarcinoma arising in an ileostomy. Arch Surg 1989; 124: 497-9.

44 Collins RH, Feldman M, Fordran JS. Colon cancer, dysplasia, and surveillance in patients with ulcerative colitis: A critical review. $N$ Engl $\mathcal{F}$ Med 1987; 316: 1654-8.

45 Sackett DL, Whelan G. Cancer risk in ulcerative colitis: scientific requirements for the study of prognosis. Gastroenterology 1980; 78: 1632-5.

46 Ekbom A, Helmick C, Zack M, Adami H-O. Ulcerative colitis and colorectal cancer. A population-based study. $N$ Engl f Med 1990; 323: 1228-33.

47 Gyde SN. Cancer risk ulcerative colitis. In: Allan RN, Keighley MRB, Alexander-Williams J, Hawkins CD, eds. Inflammatory bowel diseases. Edinburgh: Churchill Livingstone, 1990: 563-74.

48 Farmer RG, Hawk WA, Turnbull RB. Clinical patterns in Crohn's disease: a statistical study of 615 cases. Gastroenterology 1975; 68: 627-35.

49 Weitzman SA, Gordon LI. Inflammation and cancer: role of phagocyte-generated oxidants in carcinogenesis. Blood 1990; 76: 655-63.

50 Spom MB, Roberts AB. Peptide growth factors and inflammation, tissue repair, and cancer. F Clin Invest 1986; 78: 329-32.

51 Mann NS, Tsai MF, Nair PK. Barrett's esophagus in patients with symptomatic reflux esophagus. $A m \mathcal{F}$ Gastroenterol 1989; 84: 1494-6.

52 Pozharisski KM. The significance of nonspecific injury for colon carcinogenesis in rats. Cancer Res 1975; 35: colon carcir

53 Yamada M, Ohkusa T, Okayasu I. Occurrence of dysplasia and adenocarcinoma after experimental chronic ulcerative colitis in hamsters induced by dextran sulphate sodium. Gut 1992; 33: 1521-7.

54 Chalifoux LV, Bronson RT. Colonic adenocarcinoma associated with chronic colitis in cotton top marmosets, Saguinus oedipus. Gastroenterology 1981; 80: 942-6.

55 Pollard M, Luckert PH. Treatment of chemically-induced intestinal cancers with indomethacin. Proc Soc Exp Biol Med 1981; 167: 161-4

56 Narisawa T, Satoh M, Sano M, Takahashi T. Inhibition of initiation and promotion by $\mathrm{N}$-methylnitrosurea-induced colon carcinogenesis in rats by non-steroid anti-inflammatory agent indomethacin. Carcinogenesis $1983 ; 4: 1225-7$.

57 Roryagent indomethacin. Carcinogenesis 1983 , 4: 1225 ME Stolley PD, Schapiro S. A hypothesis: nonsteroidal antiinflammatory drugs reduce the incidence of large-bowe cancer. F Natl Cancer Inst 1991; 83: 355-8.

58 Rigau J, Pique JM, Rubio E, Planas R, Tarrech JM, Bordas JM. Effects of long-term sulindac therapy on colonic polyposis. Ann Intern Med 1991; 115: 952-4

59 Thun MJ, Namboodiri MM, Heath CW. Aspirin use and reduced risk of fatal colon cancer. $N$ Engl $\mathcal{F}$ Med 1991; 325: 1593-6.

60 Labayle D, Fischer D, Vielh P, Drouhin F, Pariente A Bories C, et al. Sulindac causes regression of rectal polyps in familial adenomatous polyposis. Gastroenterology 1991; 101: 635-9.

61 Choi PM. Predominance of rectosigmoid neoplasia in ulcerative colitis and its implication on cancer surveil lance. Gastroenterology 1993; 104: 666-7. 